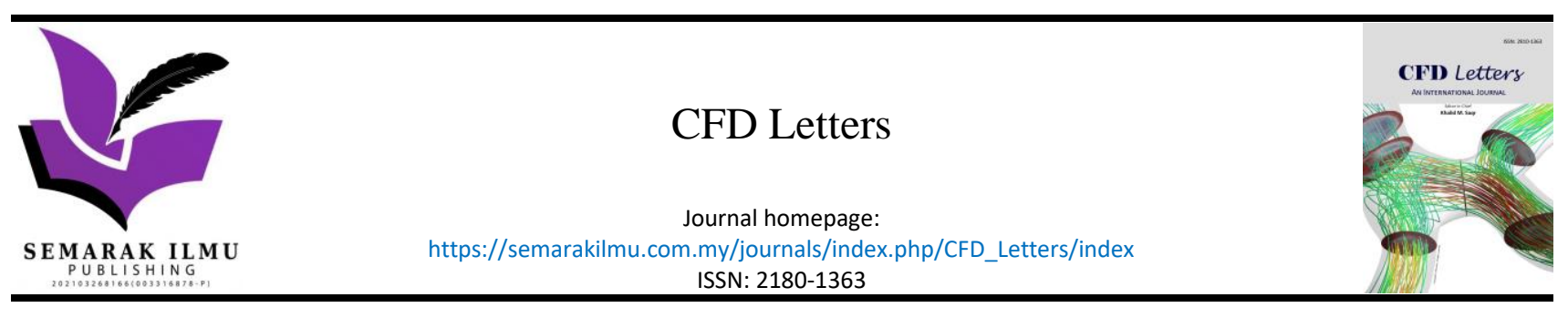

\title{
Resistance Analysis of a Hydrofoil Supported Watercraft (Hysuwac): A Case Study
}

\author{
Ketut Suastika ${ }^{1,}{ }^{*}$, Gilbert Ebenezer Nadapdap ${ }^{1}$, Muhammad Hafiz Nurwahyu Aliffrananda ${ }^{1}$, Yuda \\ Apri Hermawan ${ }^{1}$, I Ketut Aria Pria Utama ${ }^{1}$, Wasis Dwi Aryawan ${ }^{1}$
}

Department of Naval Architecture, Faculty of Marine Technology, Institut Teknologi Sepuluh Nopember (ITS), Surabaya 60111, Indonesia

ARTICLE INFO ABSTRACT

\section{Article history:}

Received 22 November 2021

Received in revised form 13 December 2021

Accepted 14 December 2021

Available online 7 January 2022

\section{Keywords:}

Catamaran; CFD; energy efficiency; Hysuwac; ship resistance

\begin{abstract}
Energy efficiency and environmental sustainability are important aspects in ship design and operation. Hull-shape optimization, hull cleaning and coating, and the use of appendages are, among others, well-known efforts to reduce ship fuel consumption. Regarding energy efficiency and environmental sustainability, it is possible to effectively reduce the resistance of an existing catamaran by retrofitting a foil system to it. In this study, a foil system is designed and retrofitted to a catamaran to reduce its total resistance. Reynolds-averaged Navier-Stokes simulations, utilizing $k-\omega$ SST turbulence model, were performed to study the effects of the foil system on the vessel's total resistance. Free surface effects were modelled, i.e., the generation of waves due to the vessel's movement on the water surface. The foil system affects the wetted surface area, running sinkage and trim, and the wave pattern generated by the vessel, which ultimately affect the vessel's total resistance. At relatively low speeds ( $\mathrm{Fr}$ $<0.7)$, an increase of the total resistance, reaching a value of approximately $11 \%$, was observed due to the foil system. However, at higher speeds ( $\mathrm{Fr}>0.7)$, the foil system decreases the total resistance, reaching a value of approximately $32 \%$ at the service speed $(\mathrm{Fr}=1.24)$. The $32 \%$ resistance reduction at the service speed is promising in view of the intended purpose of the foil system as an energy saving device.
\end{abstract}

\section{Introduction}

Environmental sustainability, energy efficiency, safety and economy are important aspects in ship design and operation. Regarding these aspects, various attempts have been made to reduce the fuel consumption of a ship, among others, optimization of the hull shape, hull cleaning, polymerase and coating, air injection, and the use of appendages as energy saving devices. Hydrofoils have been applied as energy saving device in the form of Hull Vane ${ }^{\circledR}$ applied to single-hull vessels [1-3] or applied to catamarans resulting in vessels known as hydrofoil supported catamaran (hysucat) or hydrofoil supported watercraft (hysuwac). In this study the concept of hysuwac is further explored in which a foil system is retrofitted to an existing operating catamaran to reduce the total resistance of the vessel.

\footnotetext{
* Corresponding author.

E-mail address: k_suastika@na.its.ac.id (Ketut Suastika)
} 
Catamarans have some advantages compared to monohull vessels. First, catamarans usually have a small draft so that they can operate in shallow water. Second, the slender hull shape reduces the intensity of the wave wash. Third, catamarans have wider deck and higher level of transverse stability compared with monohull vessels [4].

Earlier studies have shown that the application of hydrofoils to catamarans can reduce the total resistance of the vessel significantly. Prof. K. G. Hoppe initiated the study on hysucat and hysuwac at the University of Stellenbosch, South Africa, in the early 1980s [5,6]. Initially, a hydrofoil assisted catamaran model was tested with an unexpected resistance improvement of $40 \%$. Later, theoretical efforts to determine the hydrodynamics of the hysucat principle resulted in numerical models for design analysis of planing type hysucats which allow further design optimization and further developments of hysucats [7]. Calkins [8] developed a hybrid marine vehicle concept, called hycat, which utilized a combination of static and dynamic support. In another study, Miyata [9] designed a new-type hydrofoil catamaran and reported that the application of hydrofoils reduced the total resistance and the motion transfer-functions of the vessel.

More recently, Najafi et al., [10] investigated experimentally the hydrodynamic performance of three different hydrofoils (NACA 16, Eppler 874 and Gottingen 11k) applied to a hysucat. They reported a significant decrease in total resistance when hydrofoils were applied to the catamaran and, amongst the three foils, the Gottingen $11 \mathrm{k}$ showed best performance. Torabi et al., [11] utilized E654 Eppler foil in their numerical study of a hysucat and reported a resistance decrease of $30 \%$. A relatively small resistance reduction of $2.14 \%$ was reported by Yao et al., [12] in their numerical and experimental study on the influence of hydrofoils on the resistance of catamarans. Kazemi et al., [13] reported that the application of hydrofoils to a catamaran brings about $50 \%$ drag reduction. Li et al., [14] performed CFD simulations and reported a total resistance reduction by up to $26 \%$ due to the application of hydrofoils to a catamaran.

The installation of a hydrofoil on a catamaran provides a dynamic lift which lifts a part of the hull. This concept adopts the foil concept used in airplane wings. With the use of a hydrofoil, the vessel's weight will be partly supported by the foil and partly by the vessel's static and dynamic buoyancy. The foil lift can affect the trim and the wetted surface area of the vessel favorably, which ultimately results in the reduction of the vessel's total resistance. The hydrodynamic performance of a hysucat or hysuwac depends on the foil type used and the placing of the hydrofoils on the catamaran. Further, the magnitude of the lift generated by the foils relative to the vessel's displacement influences the vessel's hydrodynamic performance. In the case of a foil-system retrofit to an existing catamaran, as considered in this study, each case should be considered separately, and a proper foil-system arrangement should be designed prior to its application. These aspects are still insufficiently reported in the literature of hydrofoil supported catamarans. In this study, a foil-system arrangement is introduced, which is then retrofitted to an existing catamaran. The effects of the foil-system on the vessel's total resistance were investigated with the aid of computational fluid dynamic simulations (CFD). Results on the vessel's resistance are reported in this study while the results on the seakeeping performance have been reported earlier by Suastika et al., [15].

\section{Methodology}

\subsection{Description of the Catamaran and Foil System}

A $10.5 \mathrm{~m}$ long passenger catamaran is considered in this study, which was designed and built by PT. Maju Bangkit Indonesia Group, Surabaya, Indonesia. It is an asymmetric flat-side inside catamaran with two hard chines, one submerged in the water, and the other located above the water line. The service speed of the vessel is $V_{s}=24.5$ knots (corresponding to length Froude number $\mathrm{Fr}=1.24$ ). The 
main particulars of the vessel are tabulated in Table 1 . The body plan and buttock lines are shown in Figure 1.

Table 1

Main particulars of the vessel

\begin{tabular}{ll}
\hline Parameter & Value \\
\hline Length overall, LOA [m] & 10.50 \\
Breadth, $B[\mathrm{~m}]$ & 3.50 \\
Height, $H[\mathrm{~m}]$ & 1.80 \\
Draft, $T[\mathrm{~m}]$ & 0.25 \\
Block coefficient of a demihull, $C_{B}[-]$ & 0.25 \\
Longitudinal centre of gravity measured from AP, LCG [m] & 4.18 \\
Total displacement, $\Delta[\mathrm{t}]$ & 1.965 \\
Service speed, $V_{s}[\mathrm{kn}]$ & 24.5 \\
\hline
\end{tabular}

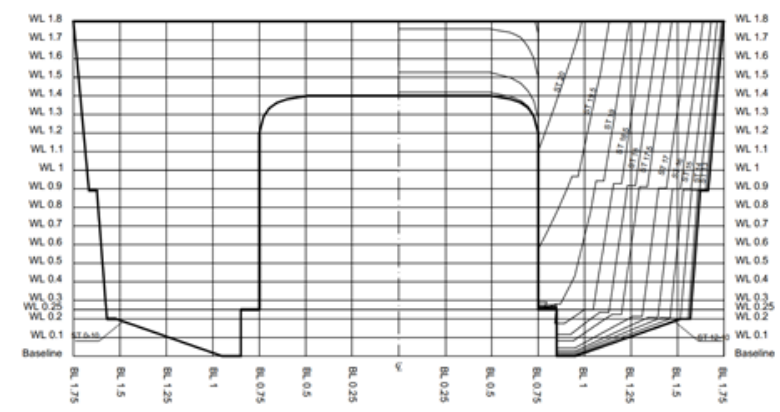

(a)

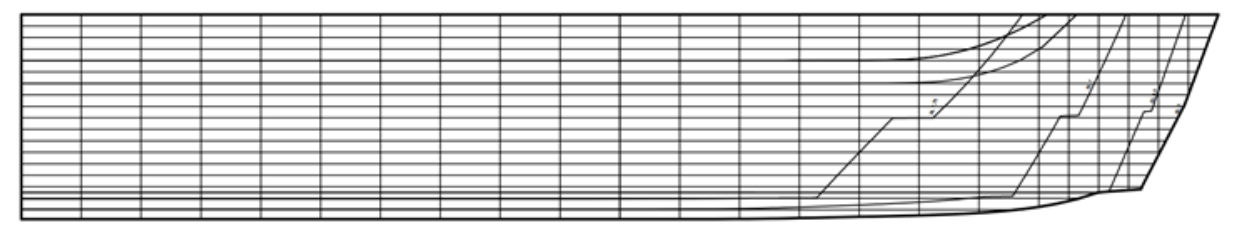

(b)

Fig. 1. Catamaran hull shape: (a) Body plan and (b) Buttock lines

The foil-system arrangement is shown in Figure 2. It is the same foil system as reported by Suastika et al., [15]. It consists of two hydrofoils, one placed near the bow while the other placed near the stern. The foils position in the longitudinal direction is indicated in Figure 2a while their submerged depth is indicated in Figure $2 b$. The foils submerged depth was determined from $h / c=$ 0.4 , where $h$ is the submerged depth and $c$ is the chord length of the hydrofoil [16]. This configuration of catamaran with foil system is called a hydrofoil supported watercraft (hysuwac) [7]. The foils section for both the bow and rear foils is the NACA 641-212 [17]. The foils span $s$ is equal to the distance between the demi hulls of the catamaran, which is $1.7 \mathrm{~m}$, and the chord length $c$ is $28 \mathrm{~cm}$ $(0.28 \mathrm{~m})$. The foil aspect ratio $A R=s / c=6.07$. CFD simulations of foil alone performed in this study showed that a maximum lift-to-drag ratio occurred at an angle of attack of approximately $4^{\circ}$. Earlier studies on the NACA 641-212 reported a maximum lift to drag ratio to occur at angle of attack approximately between $2^{\circ}$ and $4^{\circ}[3,18]$. Therefore, the angle of attack of the foils was set at $4^{\circ}$ (counter-clockwised from the vessel's course direction; the positive $x$-axis). 


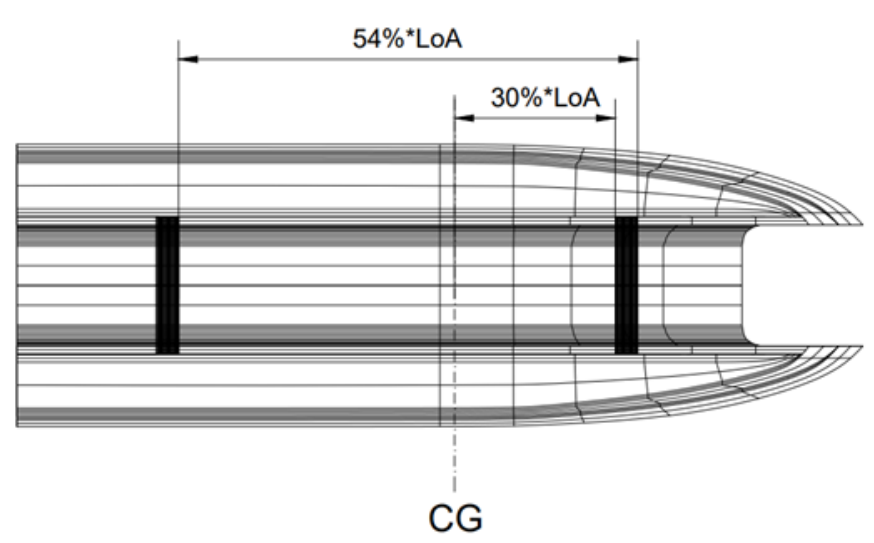

(a)

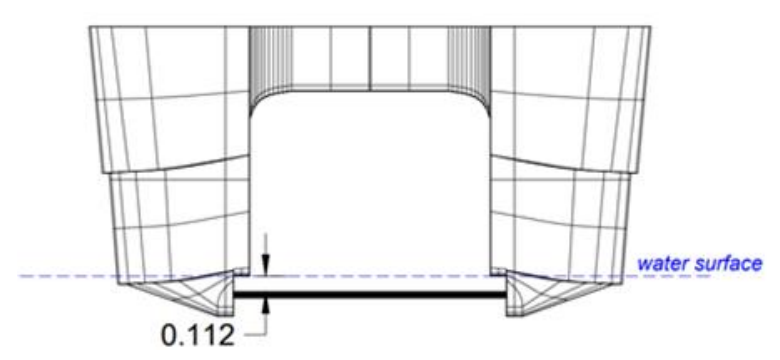

(b)

Fig. 2. The foil system applied to the catamaran: (a) Position of the hydrofoils in the longitudinal direction and (b) The foil submerged depth

\subsection{CFD Simulations of Catamaran without and with Foil System}

To study the total resistance of catamaran without and with foil system, Reynolds-averaged Navier-Stokes (RANS) simulations were performed with modelling of the free surface effects, i.e., the generation of waves due to the vessel's movement on the water surface. For that purpose, the Numeca FINE ${ }^{\mathrm{TM}} /$ Marine software package was utilized [19]. The CFD package utilizes the ISIS-CFD flow solver, developed by Ecole Centrale de Nantes and CNRS. The solver is based on the secondorder accurate finite volume method. Eqs. (1), (2) and (3) represent the mass, momentum, and volume fraction equations in integral form, respectively, for a two-phase incompressible unsteady flow considered in this study

$\frac{\partial}{\partial t} \int_{V} \rho \mathrm{d} V+\int_{S} \rho\left(\mathbf{U}-\mathbf{U}_{d}\right) \cdot \mathbf{n} \mathrm{d} S=0$

$\frac{\partial}{\partial t} \int_{V} \rho U_{i} \mathrm{~d} V+\int_{S} \rho U_{i}\left(\mathbf{U}-\mathbf{U}_{d}\right) \cdot \mathbf{n} \mathrm{d} S=\int_{S}\left(\tau_{i j} I_{j}-p I_{i}\right) \cdot \mathbf{n} \mathrm{d} S+\int_{V} \rho g_{i} \mathrm{~d} V$

$\frac{\partial}{\partial t} \int_{V} c_{i} \mathrm{~d} V+\int_{S} c_{i}\left(\mathbf{U}-\mathbf{U}_{d}\right) \cdot \mathbf{n} \mathrm{d} S=0$

In Eqs. (1-3), $\mathbf{U}$ is the velocity field relative to a stationary observer, $\mathbf{U}_{d}$ is the velocity of the control volume $V$ relative to the stationary observer, $S$ is the control surface with an outward normal vector $\mathrm{n}, \rho$ is the mass density of the fluid, $p$ is pressure, $g$ is the gravitational acceleration and $t$ is time. Further, $\tau_{i j}$ are the Reynolds stresses, $l_{i}$ is an identity tensor and $c_{i}$ is a volume fraction, representing the presence of fluid $i\left(c_{i}=1\right)$ or its absence $\left(c_{i}=0\right)$. At the free-surface interface, the value of $c_{i}$ is between zero and one $\left(0<c_{i}<1\right)$.

To close the system of Eqs. (1-2), the $k$ - $\omega$ SST turbulence model [20] was applied, which relates the Reynolds stresses $\tau_{\mathrm{ij}}$ with the mean flow properties. This turbulence model can predict the onset and amount of flow separation accurately [21]. The free surface boundary is modelled with Eq. (3) utilizing the volume of fluid (VoF) method [22]. Eq. (3) represents the transport equation for the volume fraction $c_{i}$. 


\subsubsection{Geometrical modeling}

A three-dimensional (3-D) model of the catamaran and the foils were generated with the aid of the Maxsurf Modeller [23]. To verify that the numerical model represents the prototype accurately, the hydrostatic characteristics of the model are compared with those of the prototype. The comparison is tabulated in Table 2. Table 2 shows that the differences in the hydrostatic characteristics between the prototype and the numerical model for all parameters considered are less than two percent, indicating accurate geometrical modelling results.

\section{Table 2}

Comparison of the hydrostatic characteristics between the prototype and numerical model

\begin{tabular}{llll}
\hline Parameter & Prototype & Numerical model & Percent difference [\%] \\
\hline Length overall, LOA [m] & 10.5 & 10.5 & 0 \\
Breadth, $B$ [m] & 3.5 & 3.5 & 0 \\
Height, $H$ [m] & 1.8 & 1.8 & 0 \\
Draft, $T$ [m] & 0.25 & 0.25 & 0 \\
Displacement, $\Delta[\mathrm{t}]$ & 1.965 & 1.987 & 1.11 \\
Length at water line, LWL [m] & 9.69 & 9.66 & -0.217 \\
Prismatic coefficient, $C_{P}[-]$ & 0.853 & 0.856 & 0.350 \\
Block coefficient, $C_{B}[-]$ & 0.25 & 0.25 & 0 \\
Midship coefficient, $C_{M}[-]$ & 0.287 & 0.292 & 1.71 \\
Longitudinal center of buoyancy, LCB, & 4.189 & 4.193 & 0.0954 \\
measured from AP [m] & & & \\
\hline
\end{tabular}

\subsubsection{Computational domain, boundary conditions and meshing}

The computational domain has a box shape as shown in Figure 3 with the location of the boundaries defined as follows. The inlet is located at $3 L$ upstream from the vessel while the outlet is located at $6 L$ downstream from the vessel, where $L$ is the overall length of the vessel (LOA). The side walls are located at $2 L$ aside the vessel. The bottom wall is located at $3 L$ below the vessel while the top wall is located at $3 L$ above the vessel. The length of the domain behind of the vessel was made rather long $(6 L)$ to sufficiently capture the shape of the wave pattern behind the vessel. The distances from the vessel to the top and bottom walls were also set quite large $(3 L)$ with the intention to provide sufficient space for the ship to move in two degrees of freedom, i.e., to appropriately capture the running sinkage and trim. Further, in high speed simulations ( $F r>1)$, a grid deformation can occur, which can affect the numerical stability or cause errors. For the above reasons, the computational domain was set relatively large as compared to that for simulations of displacement vessels with relatively low speeds.

The boundary conditions are defined as follows. On the inlet, outlet and side wall boundaries the velocity was defined as free stream far field velocity. On the bottom and top walls, the pressure was prescribed. The boundary condition on the vessel's hull was defined as no-slip, where a wall function was utilized. Further, the trim and sinkage of the vessel were resolved in the simulations. Because of symmetry and to reduce the required computational resource, only a half of the domain was simulated. 


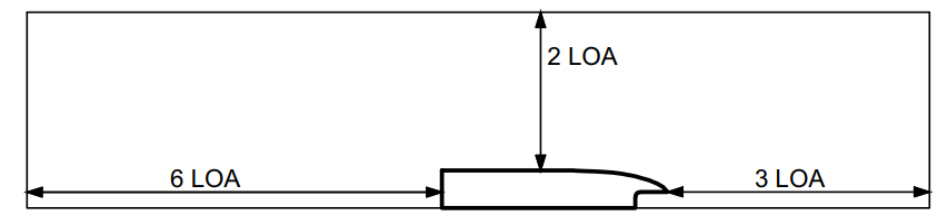

Ship Movement Direction

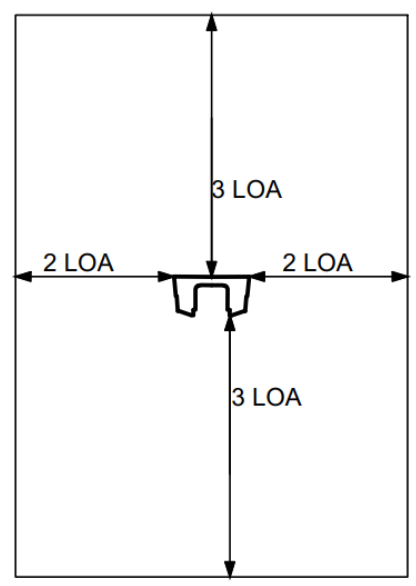

Fig. 3. Definition of the computational domain: top view (left) and cross section (right)

It is important to get an accurate picture of the fluid flow along the ship hull, i.e., the boundary layer flow which affects the drag of the vessel. Therefore, the mesh near the hull was refined. Further, the mesh near the free surface was also refined to capture the free surface effects, i.e., the waves generated by the vessel's movement on the water surface. Figure 4 shows a side view of the computational mesh, where a multi-block structured grid was utilized [24], with mesh refinements in the regions near the free surface and near the hull.

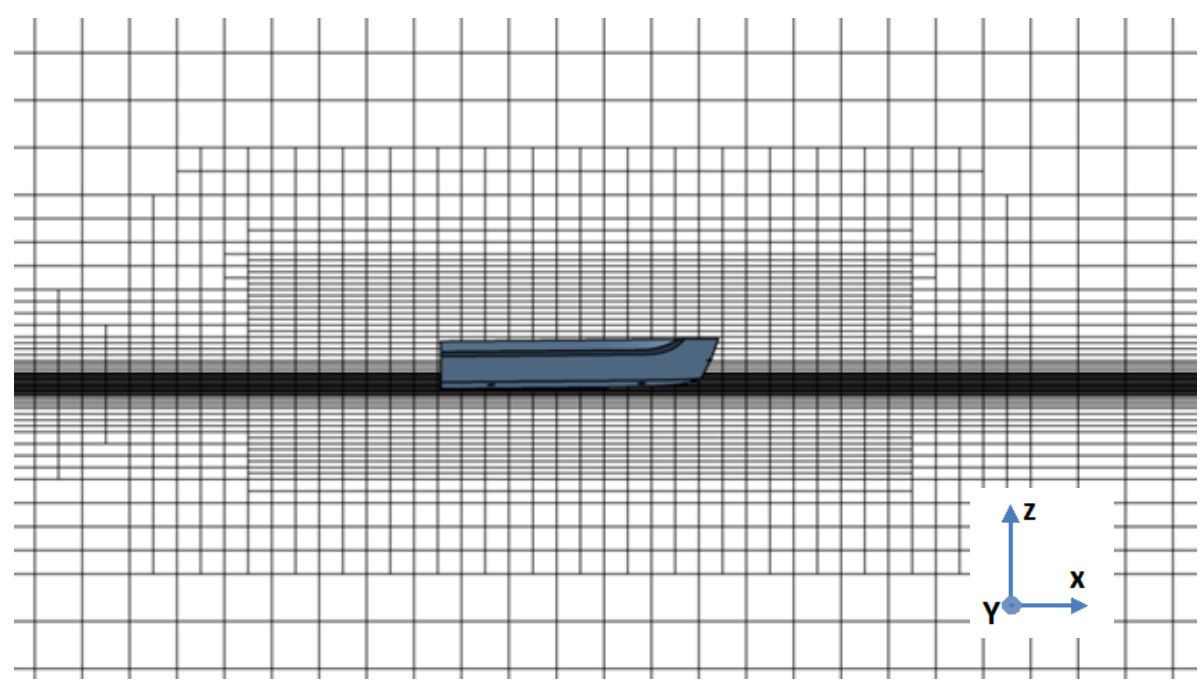

Fig. 4. Side view of the computational mesh, utilizing a multi-block structured grid, for the simulations of catamaran with and without foil system

\subsubsection{Grid independence tests}

Grid independence tests were carried out to verify the convergence of the numerical calculations and to determine the optimum number of cells to be used in the final setting of the CFD simulations. The total resistance of catamaran without foil system at the service speed $\left(V_{s}=\right.$ of $24.5 \mathrm{knots} ; \mathrm{Fr}=$ 1.24) was considered in the grid-independence tests. In these tests, the number of cells in a subsequent simulation was increased approximately one and a half times until twice from the previous one, and the percent increase or decrease of total resistance obtained from these two subsequent simulations was determined. The results are tabulated in Table 3 and plotted in Figure 5. 
In the first three simulations, the total resistance decreases, and thereafter increases slightly, as shown in Figure 5 and Table 3. Looking at the graph in Figure 5, the simulations should be carried out further after simulation number four. However, the absolute differences between two subsequent total resistances are less than two percent (see Table 3), which is considered as sufficiently accurate for the final value estimate [25]. Considering the available computational resources, the number of cells of 2669190 was considered as the most optimum value for the final simulations of catamaran without foil system. For the case of catamaran with foil system, there is an additional number of cells due to the foil system.

Table 3

Total resistance as function of number of cells used in the simulations

\begin{tabular}{lll}
\hline Number of cells & Total resistance [N] & Percent difference [\%] \\
\hline 864941 & 4593.28 & \\
1579759 & 4531.17 & -1.352 \\
2669190 & 4462.83 & -1.508 \\
5000367 & 4483.16 & +0.456 \\
\hline
\end{tabular}

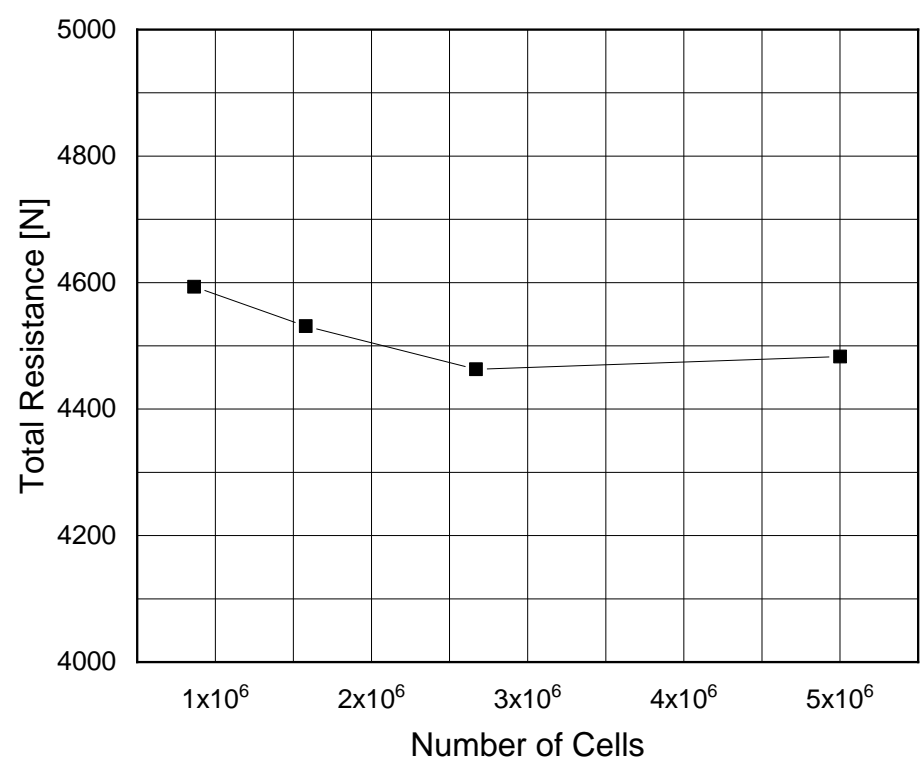

Fig. 5. Total resistance as function of number of cells used in the simulations for catamaran without foil system at the service speed $\left(V_{s}=24.5\right.$ knots; $\left.\mathrm{Fr}=1.24\right)$

\section{Results and Discussion}

Results of the total resistance of catamaran without and with foil system are presented in this section. Figure $6 a$ shows that the retrofit of the foil system results in an increase of the total resistance at $\mathrm{Fr}<0.7$ but a decrease of this at $\mathrm{Fr}>0.7$. More specifically, at $\mathrm{Fr}=0.507$ and 0.634 an increase of the total resistance was observed of $10.78 \%$ and $4.12 \%$, respectively. Further, at $\mathrm{Fr}>0.7$, the foil system reduces the total resistance with a value of $3.29 \%$ at $\mathrm{Fr}=0.760$ until a maximum reduction of $32.04 \%$ at the service speed $(\mathrm{Fr}=1.24)$. An interpretation of these results is as follows. At relatively low speeds the foil lift has not sufficiently been generated to lift the vessel while the foils work as appendages to result in an increase of the total resistance of the vessel. At high speeds the foils sufficiently generate lift force, and the foil system works as desired, i.e., to reduce the total resistance of the vessel. The $32.04 \%$ reduction of total resistance at the service speed is promising in 
view of the intended purpose of the foil system as an energy saving device. To better understand the above observations, these will be further analyzed, utilizing the results of observed wetted surface area (WSA), running sinkage and trim, and the generated wave pattern (wash) by the vessel.

The application of the foil system reduces the WSA of the vessel as shown in Figure $6 \mathrm{~b}$. The decrease in WSA due to the foil system increases with increasing speed with a maximum decrease of $68.18 \%$ at the service speed $(\mathrm{Fr}=1.24)$. This decrease in WSA is ascribed to the foils lift, which lifted the vessel as indicated by the vessel's running sinkage shown in Figure 7a. A positive sinkage means that the vessel is lifted as compared with the initial position (the reference of zero sinkage). As shown in Figure 7a, the hull lift increases with increasing speed for both catamaran with and without foil system. In the case of catamaran without foil system, a negative sinkage was observed at $\mathrm{Fr}=0.507$ and 0.634 , and the hull lift was ascribed to the hull planing. The hull lift is much larger for the case of catamaran with foil system, as expected.

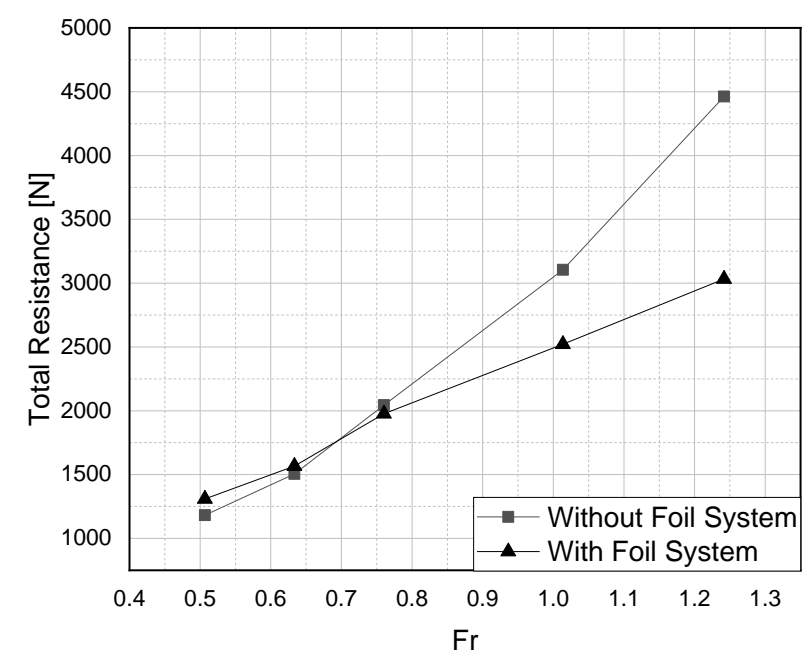

(a)

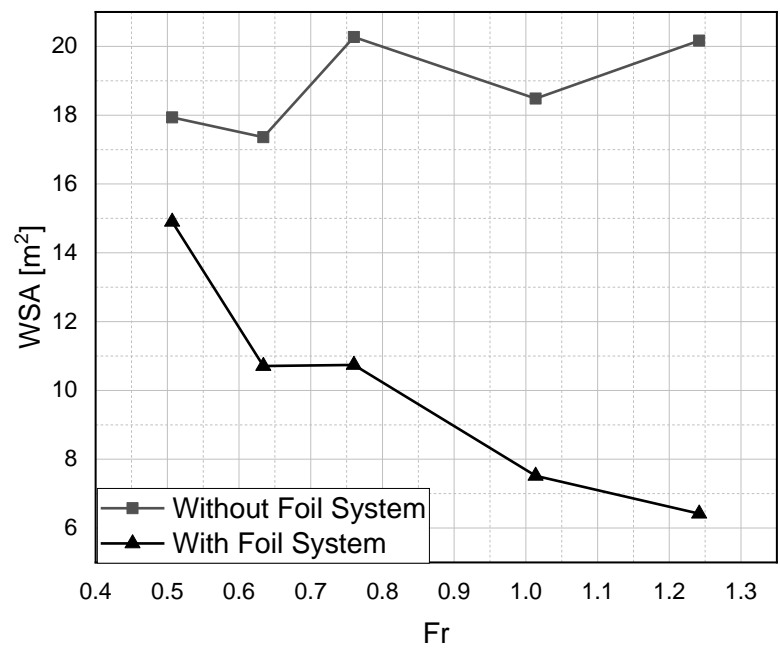

(b)

Fig. 6. Total resistance (a) and wetted surface area (b) of catamaran without and with foil system as function of Froude number

The hull lift of the vessel at the service speed $\left(V_{s}=24.5\right.$ knots; $\left.\mathrm{Fr}=1.24\right)$ is visualized in Figure 8 . Beside visualizing the hull lift, Figure 8 also shows a relatively large water spray in the case of catamaran without foil system, which is attributed to the hard chine of the vessel. On the contrary, no water spray was observed for the case of catamaran with foil system. The reduction of the water spray due to the application of the foil system also results in the reduction of the total resistance.

The decrease in WSA plays an important but not a single role in the decrease of the total resistance. As shown in Figures $6 a$ and $b$, the total resistance was observed to increase with the application of the foil system at $\mathrm{Fr}=0.507$ and 0.634 although the WSA decreases at these Froude numbers. The running trim and the wave pattern (wash) generated by the vessel also play a role in affecting the total resistance of the vessel. The running trim is plotted in Figure $7 \mathrm{~b}$, showing negative values of running trim. A negative running trim means a bow-down trim. For the case of catamaran without foil system, the bow-down trim decreases with increasing speed, ascribed to hull planing. For the case of catamaran with foil system, the bow-down trim first increases and then decreases with increasing speed. In all the cases, the bow-down running trim is less than one degree, which is relatively small. This change in running trim due to the application of the foil system also affects the vessel's total resistance. 


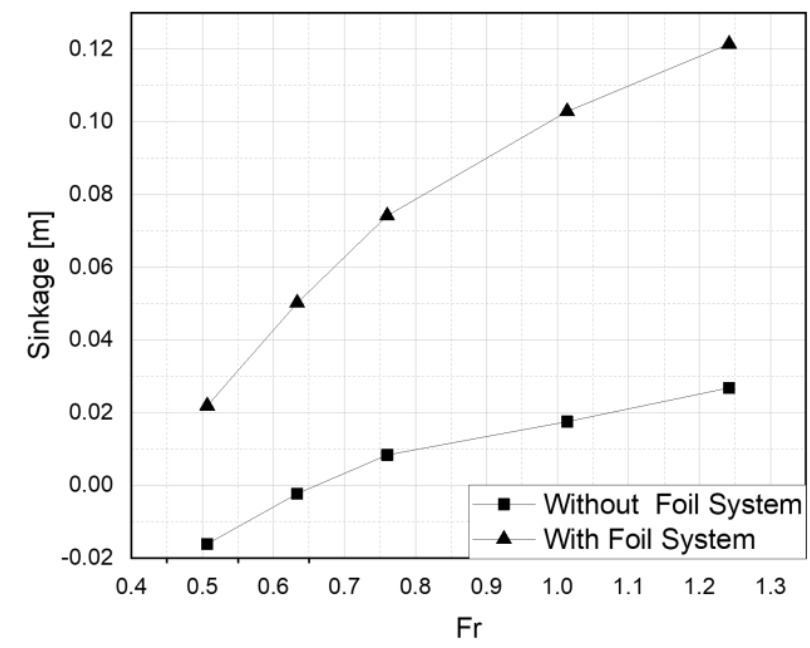

(a)

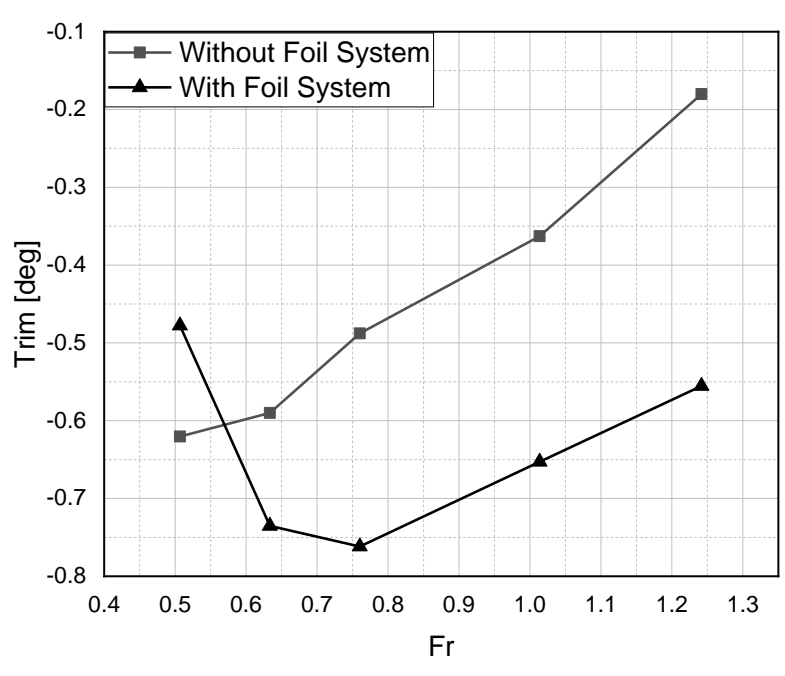

(b)

Fig. 7. Running sinkage (a) and trim (b) of the vessel as function of Froude number

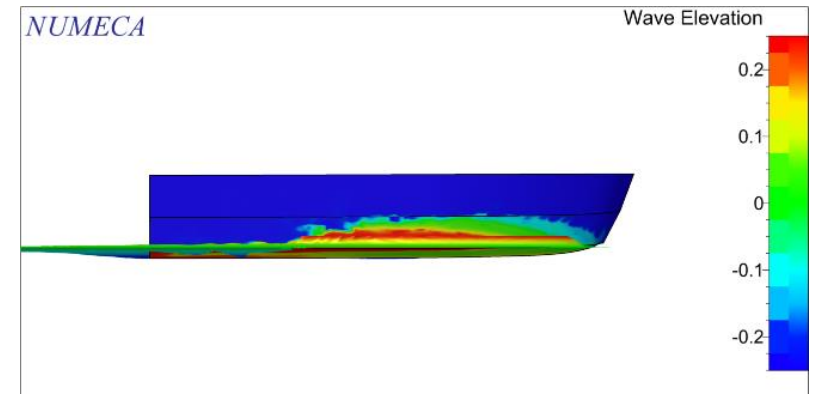

(a)

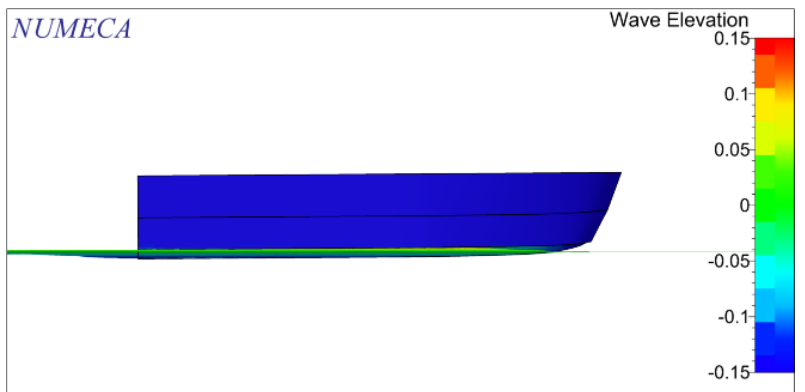

(b)

Fig. 8. Side view of the water surface along the hull at the service speed $\left(V_{s}=24.5 \mathrm{knots} ; \mathrm{Fr}=1.24\right)$ for catamaran without foil system (a) and with foil system (b)

Figures 9 and 10 show the wave patterns generated by the vessel at 10 knots ( $\mathrm{Fr}=0.507)$ and 24.5 knots $(\mathrm{Fr}=1.24)$, respectively, for catamaran without and with foil system. At relatively low speed (10 knots; $\mathrm{Fr}=0.507)$ the foil system results in higher waves behind the vessel while at high speed ( 24.5 knots; $\mathrm{Fr}=1.24)$ the foil system decreases the wave height behind the vessel as compared to the case of catamaran without foil system. The increase/decrease in wave height corresponds to an increase/decrease in the wave-making resistance. The increase in total resistance at low speeds with the application of the foil system is partly ascribed to the increase in wave-making resistance. Further, Figures 9 and 10 show that the wave patterns consist of transverse waves propagated in the direction of the vessel's course and divergent waves propagated in the direction making an angle with the vessel's course. As the speed increases, the wave pattern becomes more dominated by the divergent waves. These observations are consistent with the classical analytical predictions as described by Faltinsen [26]. 


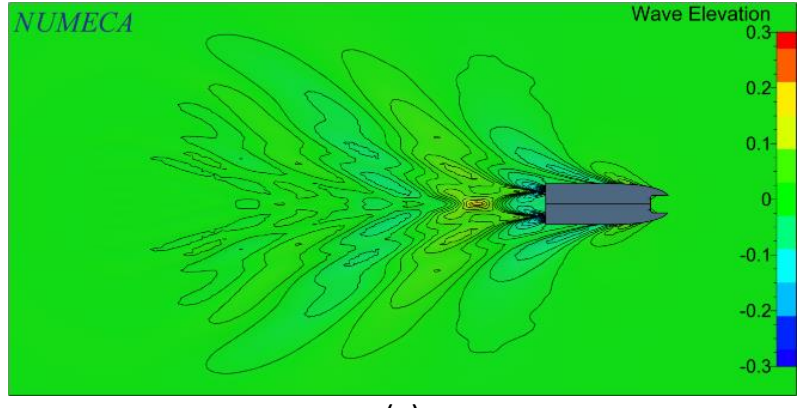

(a)

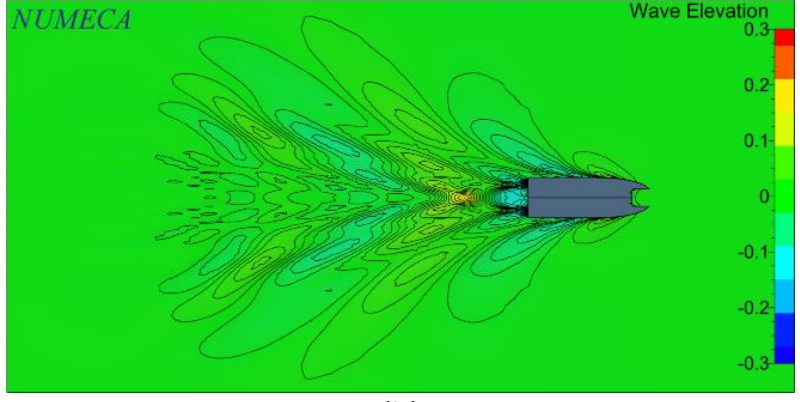

(b)

Fig. 9. Wave patterns for the vessel at 10 knots $(\mathrm{Fr}=0.507)$ : (a) Without foil system, (b) With foil system (unit of water elevation in $\mathrm{m}$ )

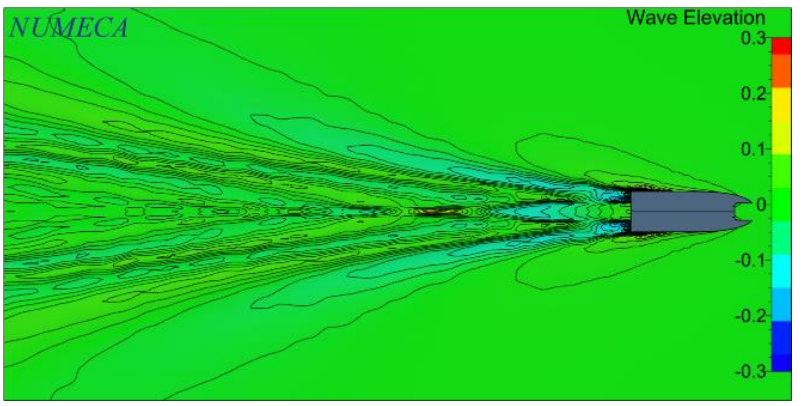

(a)

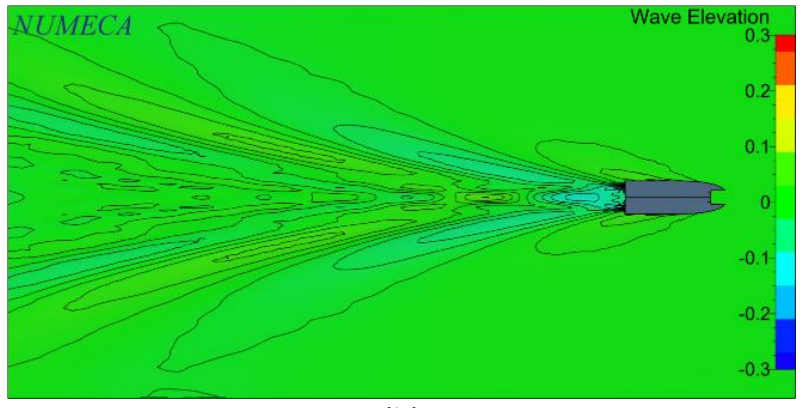

(b)

Fig. 10. Wave patterns for the vessel at 24.5 knots ( $F r=1.24)$ : (a) Without foil system, (b) With foil system (unit of water elevation in $\mathrm{m}$ )

\section{Conclusions and Recommendations}

A foil system was retrofitted to an existing catamaran to reduce the resistance of the vessel. The foil system affects the wetted surface area, running sinkage and trim, and the wave pattern generated by the vessel, which ultimately affect the vessel's total resistance. At Fr $<0.7$, the foil system increases the total resistance of the vessel, reaching a value of approximately $11 \%$ at $\mathrm{Fr}=$ 0.507. This is ascribed to that the foil lift has not sufficiently been generated to lift the vessel at low speeds while the foils work as appendages to result in an increase of the total resistance. Further, it was observed that the foil system increases the height of the waves (wash) behind the vessel at low speeds, and accordingly, it increases the wave-making resistance. At $\mathrm{Fr}>0.7$, the foils sufficiently generate the lift force, and the foil system works as desired, i.e., to reduce the total resistance of the vessel. The foil system lifted the vessel, and it reduced the vessel's wetted surface area. Further, it also affects the running sinkage and trim, and reduced the height of the waves (wash) at high speeds, thus reducing the wave-making resistance. A resistance reduction of approximately $32 \%$ was attained at the service speed $(\mathrm{Fr}=1.24)$, which is promising in view of the intended purpose of the foil system as an energy saving device.

It is recommended to verify the results of total resistance and other parameters, such as WSA, running sinkage and trim, obtained in this study by using experimental data from towing tests. As part of the present study, towing tank experiments are planned, to be carried out in near future.

\section{Acknowledgements}

The authors thank Mr. Eddy Noer Seto at PT. Maju Bangkit Indonesia Group, Surabaya, Indonesia, for providing the vessel's data and for the fruitful collaboration. This research project was supported by the Ministry of Education, Culture, Research and Technology/National Research and Innovation 
Agency (BRIN) of the Republic of Indonesia under the Grant Penelitian Dasar Unggulan Perguruan Tinggi (PDUPT) with contract no. 888/PKS/ITS/2021.

\section{References}

[1] Bouckaert, Bruno, K. Uithof, N. Moerke, and P. G. Van Oossanen. "Hull Vane on 108m Holland-Class OPVs: Effects on Fuel Consumption and Seakeeping." In Proceeding of MAST Conference. 2015.

[2] Uithof, Kasper, N. Hagemeister, B. Bouckaert, P. G. Van Oossanen, and N. Moerke. "A systematic comparison of the influence of the hull vane, interceptors, trim wedges, and ballasting on the performance of the $50 \mathrm{~m}$ AMECRE series 13 patrol vessels." Proc. Warship 2016: Advanced Tech. Naval Design, Constr. Operation, Bath, UK (2016).

[3] Suastika, Ketut, Affan Hidayat, and Soegeng Riyadi. "Effects of the application of a stern foil on ship resistance: A case study of an Orela crew boat." Int. J. Tech 8, no. 7 (2017): 1266-1275. https://doi.org/10.14716/ijtech.v8i7.691

[4] Yun, Liang, Alan Bliault, and Huan Zong Rong. High speed catamarans and multihulls: technology, performance, and applications. Springer, 2018. https://doi.org/10.1007/978-1-4939-7891-5

[5] Hoppe, K. G. "Boats, Hydrofoil Assisted Catamaran." SA Patent 80 (1980): 5400.

[6] Hoppe, K. G. "Boats, Hydrofoil Supported Catamaran." SA Patent 82 (1982): 3505.

[7] Hoppe, K. G. "Recent applications of hydrofoil-supported-catamarans." Fast Ferry International 36 (2001).

[8] Calkins, D. E. "HYCAT: hybrid hydrofoil catamaran concept." Ocean engineering 11, no. 1 (1984): 1-21. https://doi.org/10.1016/0029-8018(84)90021-0

[9] Miyata, Hideaki. "Development of a new-type hydrofoil catamaran." Journal of ship research 33, no. 02 (1989): 135144. https://doi.org/10.5957/isr.1989.33.2.135

[10] Najafi, Amin, Hashem Nowruzi, and Hassan Ghassemi. "Performance prediction of hydrofoil-supported catamarans using experiment and ANNs." Applied Ocean Research 75 (2018): 66-84. https://doi.org/10.1016/i.apor.2018.02.017

[11] Azad, M. Torabi, A. Nowruzi, and M. Sadeghi. "A numerical analysis of hydrofoil operation near the water surface and development of a method to calculate the HYSUCAT dynamic performance in the conceptual design phase." Indian Journal of Geo-Marine Sciences 47, no. 8 (2018).

[12] Yao, G., Y. Liu, Y. Zhao, and P. Qiu. "Study on the influence of hydrofoil on the resistance of catamarans based on STAR-CCM+." Wuhan Ligong Daxue Xuebao (Jiaotong Kexue Yu Gongcheng Ban)/Journal of Wuhan University of Technology (Transportation Science and Engineering) 42, no. 4 (2018).

[13] Kazemi Moghadam, H., Rouzbeh Shafaghat, and A. Hajiabadi. "Foil Application to Reduce Resistance of Catamaran under High Speeds and Different Operating Conditions." International Journal of Engineering 32, no. 1 (2019): 106111. https://doi.org/10.5829/ije.2019.32.01a.14

[14] Li, H. J., A. M. F. Putra, K. Sun, J. X. Leng, H. X. Zhao, and J. H. Chen. "Boat Trial Validation and Resistance Prediction of a 36-Foot Hydrofoil Catamarans Using CFD." Chuan Bo Li Xue/Journal of Ship Mechanics 24, no. 6 (2020).

[15] Suastika, Ketut, Agung Silaen, Muhammad Hafiz Nurwahyu Aliffrananda, and Yuda Apri Hermawan. "Seakeeping Analysis of a Hydrofoil Supported Watercraft (Hysuwac): A Case Study." CFD Letters 13, no. 5 (2021): 10-27. https://doi.org/10.37934/cfdl.13.5.1027

[16] Hoppe, Karl-Gunther W. "Catamaran with hydrofoils." U.S. Patent 4,606,291, issued August 19, 1986.

[17] Abbott, Ira H., and Albert E. Von Doenhoff. Theory of wing sections: including a summary of airfoil data. Courier Corporation, 2012.

[18] Suastika, Ketut, Ahmad Firdhaus, Rajabal Akbar, Wasis Dwi Aryawan, I Ketut Aria Pria Utama, Soegeng Riyadi, and Bharathram Ganapathisubramani. "Experimental and numerical study of ship resistance due to variation of hull vane ${ }^{\circledR}$ positioning in the longitudinal direction." in Proceedings of International Conference on Ship and Offshore Technology. 2019.

[19] Numeca International. "FINE/Marine 7.2 Theory Guide." Belgium, 2018.

[20] Menter, Florian R. "Two-equation eddy-viscosity turbulence models for engineering applications." AIAA journal 32 no. 8 (1994): 1598-1605. https://doi.org/10.2514/3.12149

[21] Bardina, J. E., P. G. Huang, and T. J. Coakley. Turbulence modeling validation, testing. and development, technical report, NASA, US. NASA Technical Memorandum, 1997. https://doi.org/10.2514/6.1997-2121

[22] Hirt, C.W. and B. D. Nichols. "Volume of fluid (VOF) method for the dynamics of free boundaries." Journal of Computational Physics 39, no. 1 (1981): 201-225. https://doi.org/10.1016/0021-9991(81)90145-5

[23] Maxsurf. "MAXSURF Naval Architecture Software." 2021.

[24] Ferziger, Joel H. and Milovan Perić. Computational methods for fluid dynamics. 3rd Ed. Berlin: springer, 2002. https://doi.org/10.1007/978-3-642-56026-2

[25] Anderson Jr., John D. Computational fluid dynamics: the basics with applications. New York: McGraw-Hill Inc., 1995. 
CFD Letters

Volume 14, Issue 1 (2022) 87-98

[26] Faltinsen, Odd M. Hydrodynamics of high-speed marine vehicles. Cambridge university press, 2005. https://doi.org/10.1017/CBO9780511546068 